\title{
Ab initio studies of propene epoxidation on oxidized silver surfaces
}

\author{
L. M. Molina, ${ }^{* a}$ M. J. López, ${ }^{a}$ and J. A. Alonso ${ }^{a}$ \\ Received Xth XXXXXXXXXX 20XX, Accepted Xth XXXXXXXXX 20XX \\ First published on the web Xth $X X X X X X X X X X 200 X$ \\ DOI: 10.1039/b000000x
}

$\mathrm{Ab}$ initio density functional simulations have been performed to study the adsorption of propene on partially oxidized silver surfaces and its interaction with surface oxygen. Two different adsorption conformations for propene are studied, with the molecule either intact or forming an $\mathrm{Ag}_{-} \mathrm{C}_{3} \mathrm{H}_{6}-\mathrm{O}$ oxymetallacycle (OMC) intermediate. Then, pathways for propene oxide, acrolein and propanone formation have been studied in detail, providing insight on the selectivity of the surfaces. We find that formation of acrolein must necessarily take place from $\mathrm{OMC}$ intermediates, requiring at least two neighbouring reactive surface oxygen anions. This suggests a strong relation between the concentration of surface oxygen and the selectivity of these surfaces.

\section{Introduction}

Propene oxide $\left(\mathrm{C}_{3} \mathrm{H}_{6} \mathrm{O}\right)$ represents a very important precursor in the production of a broad variety of commodity chemicals ${ }^{1}$. Traditionaly, it has been produced by complex, expensive and environmentaly unfriendly processes, which create many byproducts and waste. For this reason, the search for a more direct and inexpensive synthesis route has received considerable attention during the last 10 years. In 1998, Haruta and coworkers showed that small gold nanoparticles supported on $\mathrm{TiO}_{2}$ form a promising heterogeneous catalyst for the direct epoxidation of propene by an $\mathrm{H}_{2} / \mathrm{O}_{2}$ gas mixture ${ }^{2}$. Afterwards, a lot of effort has been devoted to clarifying the mechanisms of the reaction (active sites, pathways, etc...) in order to improve their performance. The ultimate goal is to produce more active catalysts with higher conversion rates and lower hydrogen consumption. Among the various aspects of the catalysts' performance that have been analyzed, two of the main ones are the influence of particle size and the type of oxide support on the activity and selectivity ${ }^{3-5}$. Particles with a size of 2-5 $\mathrm{nm}$ seem to provide the best selectivity, although small gold clusters containing only a few atoms have also been found active for this reaction ${ }^{6}$. Concerning the type of support, the most active catalysts are found supported on mesoporous titanosilicates $^{7-10}$; on these systems, a reaction mechanism has been proposed based on hydrogen peroxide $\left(\mathrm{H}_{2} \mathrm{O}_{2}\right)$ synthesis at the gold nanoparticles, followed by oxidation of propene at $\mathrm{Ti}$ sites isolated within the $\mathrm{SiO}_{2}$ network. In the case of $\mathrm{TiO}_{2}$ substrate, the oxide/gold interfacial region seems to play a very important role, with propene reacting there with surface oxygen atoms to form key oxymetallacycle (OMC) intermedi-

a Departamento de Física Teórica, Universidad de Valladolid, E-47011 Valladolid, Spain. Fax: (34) 983423013; Tel: (34) 983185062; E-mail: lmolina@fta.uva.es $\operatorname{ates}^{11}$.

Aside from activity and selectivity, another key issue is the hydrogen consumption. There is an active search for systems where it is only sparingly used or even not necessary for $\mathrm{O}_{2}$ activation to peroxo species. With this purpose, the alternative approach of using clusters or nanoparticles of other noble metals or alloys is currently being studied ${ }^{14}$; it is well known that silver is a very active and widely used catalyst for the epoxidation of ethene ${ }^{15-19}$. However, when trying to use this metal for epoxidation of larger alkenes, problems arise because of the competitive oxidation of terminal $-\mathrm{CH}_{3}$ groups to an aldehyde $^{20-22}$, which makes obtention of a highly selective catalyst problematic. This approach has been the focus of recent experiments in the group of S. Vajda, where it has been shown that supported Ag nanoparticles are actually able to directly epoxidize propene from $\mathrm{O}_{2}$, although the aldehyde by-product (acrolein) is also produced ${ }^{23}$. Interestingly, the selectivity was found to be highly dependent on the size of the nanoparticles.

All of this has motivated us to perform a detailed study of the reaction pathways for various products that are likely to be formed upon reaction of propene with oxidized silver surfaces. Considering various types of surface reconstructions which are likely to exist in the temperature and pressure range at which the reaction takes place, we have evaluated the adsorption energy of propene, both as an intact entity as well as in the form of oxymetallacycle intermediates, which are found to play a crucial role during epoxidation of alkenes in a broad variety of situations $11,24,25$. Then, we have analyzed in detail the selectivity of these catalysts by comparing the various reaction pathways for either propene oxide, acrolein or propanone production. 


\section{Computational setup}

The ab initio density functional calculations for the partial oxidation of propylene were carried out using the DACAPO code $^{26}$, which expands the wavefunctions in a plane-waves basis set ${ }^{27}$, and uses ultrasoft pseudopotentials ${ }^{28}$ for treating the electron-ion interaction. The PW91 functional ${ }^{29}$ was used for exchange-correlation, and a 30 Ryd cutoff energy was employed for the plane waves expansion of the wave functions. It was tested that such value gives binding energies which are converged within $0.05 \mathrm{eV}$. The partially oxidized $\mathrm{Ag}(111)$ surface was modeled using a 4-layer metal slab, with the oxide on the first one. The first two layers are relaxed, while the two layers at the bottom are kept frozen at their bulk positions. The unit cells in the $\mathrm{x}$ and $\mathrm{y}$ directions are large enough (see discussion below) as to prevent sizable mutual interactions between adsorbed propene molecules in neighbouring unit cells. A $(2 \times 2 \times 1)$ k-point sampling was found to give converged total energies for the unit cells employed. The vacuum separation between slabs was set to $11 \AA$, ensuring binding energies converged within $0.01 \mathrm{eV}$. It was tested that, for this type of surfaces, dipole corrections were negligible. For each structure, the electronic degrees of freedom were optimized until total energies were converged with a precision of $5 \cdot 10^{-5} \mathrm{eV}$. On each reaction stage, the equilibrium structures were found by a BFGS optimization ${ }^{30}$, until the maximum force on the atoms was below $0.03 \mathrm{eV} / \AA$ (ensuring a precision in binding energies better than $0.01 \mathrm{eV}$ ).

Energy barriers were calculated by a constrained minimization method, involving several simulations where the reaction coordinate ( $\mathrm{C}-\mathrm{O}$ or $\mathrm{C}-\mathrm{H}$ bond distance) was restricted at increasingly smaller values, while allowing the rest of the system to freely relax ${ }^{31}$. At distances nearby the transition state, various possible conformations of the molecule are relaxed under the mentioned bond distance constraints, until a reliable transition state (characterized by a local energy maximum) is found.

\section{$3 \quad \mathbf{C}_{3} \mathbf{H}_{6}$ adsorption}

Figure 1 shows the relaxed structures for two alternative models of the silver surface oxide ${ }^{32,33}$, with either $\mathrm{Ag}_{1.83} \mathrm{O}$ (top) or $\mathrm{Ag}_{2} \mathrm{O}$ (bottom) stoichiometry. The motivation for studying such two different situations arises from their qualitatively different character. In the first case $\left(\mathrm{Ag}_{1.83} \mathrm{O}\right)$ there are two different types of $\mathrm{Ag}$ atoms, either non-oxidized (the ones in the center of Ag-O hexagons) or oxidized. Overall, within the considered unit cell (shown in Fig. 1), the oxidized first layer contains 11 silver atoms ( 9 oxidized, and 2 non-oxidized) and 6 oxygen atoms, giving an overall stoichiometry of $\mathrm{Ag}_{11} \mathrm{O}_{6}$, which we label as $\operatorname{Ag}_{1.83} \mathrm{O}$. In the other case $\left(\mathrm{Ag}_{2} \mathrm{O}\right)$ all silver atoms are oxidized, forming strong bonds with surface oxygen anions. The depicted unit cell contains 12 silver and 6 oxygen atoms. Choosing such structures for partially oxidized silver is motivated by recent experimental and theoretical studies of this surface. Early Scanning Tunneling Microscopy (STM) studies by the group of D. A. King ${ }^{34,35}$ proposed a $\mathrm{Ag}_{1.83} \mathrm{O}$ conformation for the oxidized $\operatorname{Ag}(111)$ surface (later on, this model of the surface has been used to perform simulations of ethene epoxidation). More recently, STM experiments by Schmid et al. ${ }^{36}$ and by Schnadt et al. ${ }^{37}$, both supported by DFT simulations, suggest that the $\mathrm{Ag}_{2} \mathrm{O}$ model of the surface reproduces more accurately the observed features.
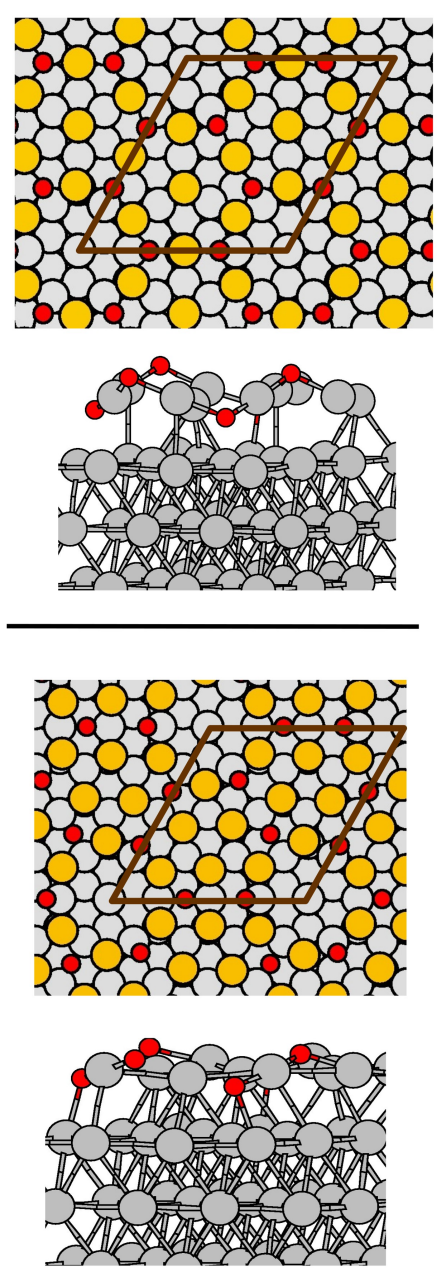

Fig. 1 Structure of $\mathrm{Ag}_{1.83} \mathrm{O}$ (upper panel) and $\mathrm{Ag}_{2} \mathrm{O}$ (bottom panel) surface oxides. The views in the upper part show a large region of the surface, with the rombohedral unit cell highlighted. Large and small circles represent $\mathrm{Ag}$ and $\mathrm{O}$ atoms, respectively. For clarity, the silver atoms in the oxidized layer are highlighted in color. The views at the lower part show the side section of the four-layers slab employed in the simulations.

First we consider the possible adsorption configurations of 
propene $\left(\mathrm{C}_{3} \mathrm{H}_{6}\right)$ at either of the surface oxides. The relaxed structures and binding energies for adsorption of one propene molecule per unit cell are shown in Figure 2. The propene binding energy $\mathrm{BE}\left(\mathrm{C}_{3} \mathrm{H}_{6}\right)$ is defined as:

$$
\mathrm{BE}\left(\mathrm{C}_{3} \mathrm{H}_{6}\right)=\mathrm{E}\left(\mathrm{C}_{3} \mathrm{H}_{6}\right)+\mathrm{E}\left(\mathrm{Ag}_{x} \mathrm{O}_{y}\right)-\mathrm{E}\left(\mathrm{C}_{3} \mathrm{H}_{6} / \mathrm{Ag}_{x} \mathrm{O}_{y}\right)
$$

that is, the difference between the sum of the energies of the separate fragments (gas-phase propene and the silver oxide surface) and the total energy of the propene molecule adsorbed on the surface. Negative values therefore represent endothermic (i.e., unfavourable) binding. We will focus on the two key reaction stages, namely the initial adsorption of propene through interaction between the substrate and the intact double $\mathrm{C}=\mathrm{C}$ bond, and the formation of strongly bound oxymetallacycle (OMC) intermediate compounds. In the latter case, the double $\mathrm{C}=\mathrm{C}$ bond breaks while two covalent bonds (a $\mathrm{C}$ $\mathrm{O}$ bond and a C-Ag bond) are formed with the surface. This type of reaction intermediates have been identified as crucial during the process of formation of epoxides, both in the case of ethene epoxidation on silver catalysts ${ }^{38}$, as well as in the case of propene epoxidation on gold nanocatalysts ${ }^{6,11}$. The final stage of either ethene oxide or propene oxide production then involves the closing of the $\mathrm{C}-\mathrm{C}-\mathrm{O}$ cycle by breaking the $\mathrm{O}$-surface covalent bond and at the same time forming a new $\mathrm{C}-\mathrm{O}$ bond, followed by desorption of the product from the surface. In the case of propene epoxidation on gold, there is ample evidence that such process takes place right at the gold-oxide interface ${ }^{11}$

The upper panel in Figure 2 shows various adsorption configurations for intact propene and for the oxymetallacycle at the $\mathrm{Ag}_{1.83} \mathrm{O}$ surface oxide, which is characterized by the coexistence of unoxidized and oxidized surface $\mathrm{Ag}$ atoms. The isomer in (a) represents the most stable configuration, with the $\mathrm{C}=\mathrm{C}$ bond on top of the unoxidized $\mathrm{Ag}$ atom which lies in the middle of the Ag-O-Ag-O honeycomb structure. The adsorption energy is moderate, $0.37 \mathrm{eV}$, and the $\mathrm{C}$ - $\mathrm{Ag}$ bond distances are not too short (2.5-2.6 $\AA$ ), indicating that the chemical interaction between the double $\mathrm{C}=\mathrm{C}$ bond and the metal atom is not strong. On the contrary, in configuration (b) the propene $\mathrm{C}=\mathrm{C}$ bond interacts strongly with an oxidized $\mathrm{Ag}$ atom, and the C-Ag bond distances are much shorter, about $2.2 \AA$; however, the binding energy of propene is smaller $(0.15 \mathrm{eV})$. This happens because the total binding energy includes the cost of the surface reconstruction taking place during propene adsorption, which in this case is quite high; the $\mathrm{Ag}$ atom is lifted up, while one oxygen atom moves down. As a result, despite of an intrinsically stronger binding of propene with the surface $\mathrm{Ag}$ atom, such conformation becomes less stable. It must be noted that the structural arrangement in (b), as well as the binding energy, are almost identical to the conformation found by Bocquet and Loffreda for ethene adsorption on the same type of surface silver oxide ${ }^{38}$.
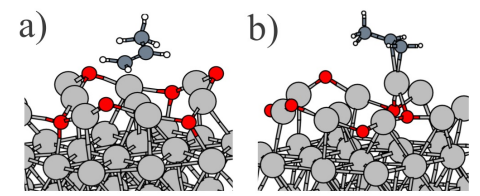

$0.37 \mathrm{eV}$

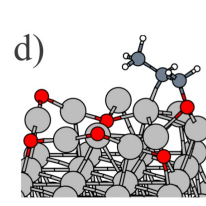

$0.00 \mathrm{eV}$

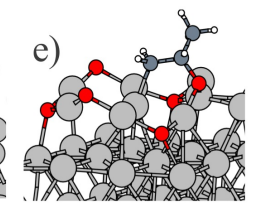

$-0.07 \mathrm{eV}$

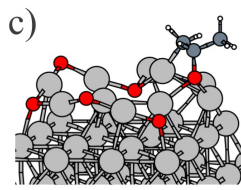

$0.22 \mathrm{eV}$

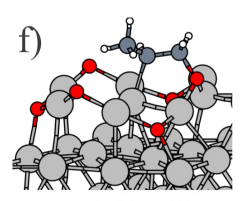

$-0.25 \mathrm{eV}$

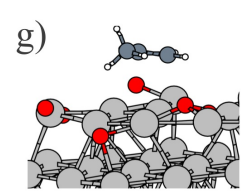

$0.16 \mathrm{eV}$

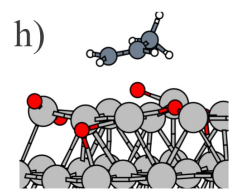

$-0.03 \mathrm{eV}$

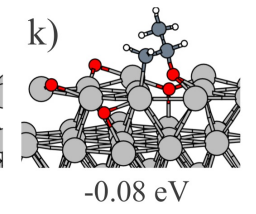

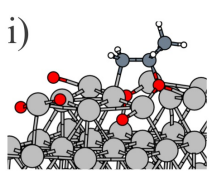

$0.03 \mathrm{eV}$

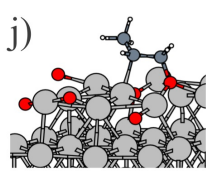

$-0.14 \mathrm{eV}$
$-0.08 \mathrm{eV}$
Fig. 2 Some relevant structures and binding energies for $\mathrm{C}_{3} \mathrm{H}_{6}$ adsorption at $\mathrm{Ag}_{1.83} \mathrm{O}$ (upper panel) and $\mathrm{Ag}_{2} \mathrm{O}$ (lower panel) surface oxides. See main text for definition of binding energy.

We have also studied the intrinsic stability of OMC intermediates (conformations (c), (d), (e) and (f)) on this surface. Isomer (c) represents the most stable situation, with one of the propene carbon atoms covalently bonded to an oxidized $\mathrm{Ag}$ atom. The moderate binding energy, $0.22 \mathrm{eV}$, indicates a relatively weak character of the $\mathrm{C}-\mathrm{O}$ and $\mathrm{C}-\mathrm{Ag}$ covalent bonds, which barely compensate for the breaking of the double $\mathrm{C}=\mathrm{C}$ bond. Isomer (d) represents a situation similar, but not equivalent to (c); in conformer (c) the surface oxygen atom binds to the middle carbon atom of propene, while in conformer (d) oxygen binds to the terminal carbon atom. For the relaxed structures, we find a preference of around $0.15-0.20 \mathrm{eV}$ for the binding of oxygen to the central carbon atom. Moreover, we have checked that this is a general feature of the oxymetallacycle intermediates; the stability of the OMC conformer bonded to oxygen through the middle carbon atom is systematically $0.15-0.20 \mathrm{eV}$ more stable than its terminal-C counterpart (conformers (e) and (f), as well as (i) and (j) in Fig. 2 show a confirmation of this effect). We have also considered OMC conformations where the OMC is bonded to a non-oxidized Ag atom (see (e) and (f)); the binding is slightly weaker, and the binding energies are slightly endothermic with respect to 
gas-phase propene.

The results for propene adsorption at the $\mathrm{Ag}_{2} \mathrm{O}$ surface oxide are shown in the lower panel of Figure 2. Conformations $(\mathrm{g})$ and $(\mathrm{h})$ represent adsorption of intact propene on the two unequivalent types of surface $\mathrm{Ag}$ atoms, which are both oxidized for this type of oxide. In both cases the binding is quite weak (smaller than $0.2 \mathrm{eV}$ ), confirming the more reactive character of non-oxidized metal atoms towards the initial adsorption of propene. The formation energy of the OMC intermediates is, as it also happened for $\operatorname{Ag}_{1.83} \mathrm{O}$, rather small, being thermoneutral or slightly endothermic (conformations i-k).

\section{Reactivity and selectivity at $\mathrm{Ag}_{1.83} \mathrm{O}$ surface oxide}

We now discuss the reaction pathways for either propene oxide $\left(\mathrm{CH}_{3} \mathrm{CHCH}_{2} \mathrm{O}\right)$, propanone $\left(\mathrm{CH}_{3} \mathrm{COCH}_{3}\right)$ or acrolein $\left(\mathrm{CH}_{2} \mathrm{CHCHO}\right)$ formation at the $\mathrm{Ag}_{1.83} \mathrm{O}$ surface oxide. To do this, we will make use of a reasonable assumption: all these products can be formed starting from a common reaction intermediate, namely the adsorbed oxymetallacycle. The pathway towards propene oxide involves the formation of a covalent $\mathrm{O}-\mathrm{C}$ bond. We will later see that the simulations show that this step takes place together with the breaking of the oxygen-surface bonds. On the other hand, the first step towards acrolein production involves the reaction between one of the hydrogen atoms in the methyl group of the adsorbed OMC intermediate and a neighbouring surface oxygen atom. Finally, the formation of either propanal or propanone involves hydrogen transfer from one of the carbon atoms in the double $\mathrm{C}=\mathrm{C}$ bond of propene to the other carbon atom, with simultaneous formation of a double $\mathrm{C}=\mathrm{O}$ bond.

We start by considering propene adsorbed on oxidized Ag atoms. Figure 3 shows the relative energies (with respect to gas-phase propene) and the corresponding relaxed structures for several key steps of the reaction. It must be noted that, in order to find favourable reaction pathways, two different OMC conformations are considered for either propene oxide or acrolein production. The reason lies in the requirement of a close distance between the propene methyl group and surface oxygen atoms. The most stable OMC arrangement in this surface (conformer (c) in Fig. 2), characterized by a 0.22 eV binding energy, has a methyl group far from any surface oxygen, making its dehydrogenation very difficult. Therefore, we have only evaluated, from such conformation, the energy barrier towards propene oxide formation. If we consider the slightly less stable alternative conformation with the OMC bonded to oxygen through the terminal $\mathrm{C}$ atom (configuration (d) in Fig. 2), now the situation changes and it becomes feasible for one of the $\mathrm{H}$ atoms in the propene methyl group to react with a neighbouring surface oxygen atom. Therefore, we have

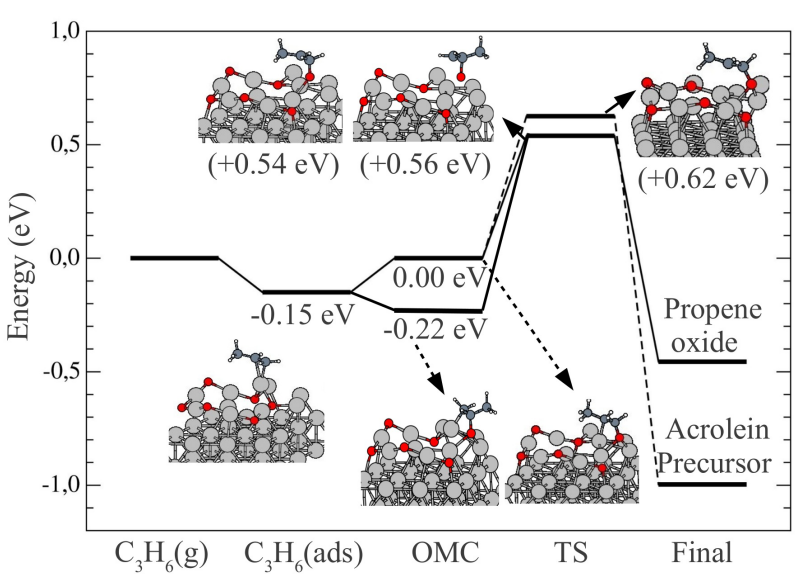

Fig. 3 Pathways for either acrolein or propene oxide formation at the $\mathrm{Ag}_{1.83} \mathrm{O}$ surface oxide. The energy reference $(0.0 \mathrm{eV})$ is taken as the energy of the gas-phase propene molecule far from the surface (that is, energy values reflect binding energies with reversed sign).

evaluated three possible energy barriers, correponding respectively to the propene oxide formation from configurations (c) and (d), and to the propene dehydrogenation from configuration (d). In all cases, the barriers are moderate (of the order of 0.6-0.8 eV), suggesting that both propene oxide and acrolein can be produced during the reaction. The relaxed structures as well as the corresponding potential energies for each transition state are shown as insets in Figure 3.

In the case of propene oxide formation, it is interesting to analyze the energy barriers for each of the two OMC conformations studied. The barrier for isomer (c) is $0.2 \mathrm{eV}$ higher than the one for isomer (d). We have found that this difference arises solely because of the stability difference between the initial states; the relative energies of the transition states in both cases are nearly the same $(+0.54$ and $+0.56 \mathrm{eV})$. One can understand this fact by looking at the relaxed transition state (TS) structures, which are almost identical. The transition states are both characterized by a bond distance for the C-O bond being formed of around $2.0 \AA$. On each case, we also find a very weak interaction between the forming propene oxide entity and the surface, with rather large oxygen-surface bond distances. Given the structural similarities, it is no surprising to find similar binding energies. We will later see that the weak interaction of the propene oxide transition state with the surface is a general characteristic of this type of oxide surfaces, as it also occurs for the $\mathrm{Ag}_{2} \mathrm{O}$ surface.

For the formation of acrolein, the energy barrier for the first reaction step, involving transfer of hydrogen from the methyl group to the surface, is $0.62 \mathrm{eV}$, very similar to the ones for propene oxide formation. This means that, in principle, the catalysts will be equally selective for propene oxide 
or acrolein. However, the higher stability of the (c) conformation, which can lead only to propene oxide formation, suggests that the catalyst will be more selective towards propene oxide. As for the structural characteristics of the transition state for acrolein production, we find an $\mathrm{O}-\mathrm{H}$ distance of $1.6 \AA$, and a $\mathrm{C}-\mathrm{H}$ distance of $1.18 \AA$. At this point, the $\mathrm{C}-\mathrm{H}$ bond is quite weakened, but still keeps its integrity. For smaller O-H distances, the $\mathrm{C}-\mathrm{H}$ bond completely breaks. It must be noted that the process of formation of the $\mathrm{O}-\mathrm{H}$ bond also takes place together with the breaking of the $\mathrm{C}-\mathrm{Ag}$ bond between the $\mathrm{OMC}$ and the surface; this bond is almost broken for the transition state.

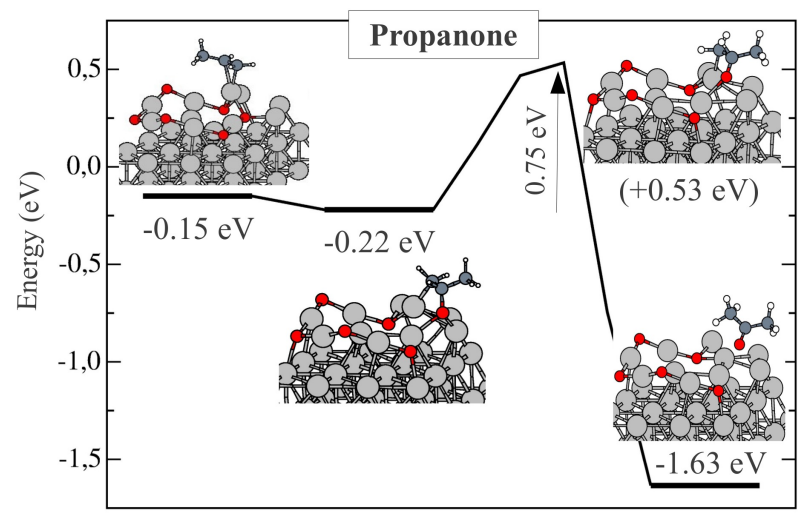

Fig. 4 Pathway for propanone formation at the $\mathrm{Ag}_{1.83} \mathrm{O}$ surface oxide. The OMC is formed at oxidyzed Ag atoms. Same energy conventions as in Figure 3.

We have also considered the formation of propanone $\left(\mathrm{CH}_{3} \mathrm{COCH}_{3}\right)$ starting from the OMC conformation shown in Fig. 2c. It must be noted that formation of propanal $\left(\mathrm{CH}_{3} \mathrm{CH}_{2} \mathrm{CHO}\right)$ is also a feasible process, provided that the initial OMC conformation has the oxygen atom bonded to the terminal carbon atom (that is, as in the conformation shown in Fig. 2d). However, since this conformer is $0.2 \mathrm{eV}$ less stable than the conformation shown in Fig. 2c, it is clear that the surface will be more selective towards propanone formation. Therefore, we have only analyzed the production of propanone. The results for the energy barrier are shown in Figure 4. We obtain a barrier height of $0.75 \mathrm{eV}$, almost the same as the one for propene oxide formation from the same $\mathrm{OMC}$ reaction intermediate. This suggests a comparable selectivity of this oxide surface towards both propene oxide and propanone. At the transition state, the hydrogen atom being transferred is located around $1.55 \AA$ away from the terminal carbon atom. Interestingly, at the TS the molecule is now still relatively close to the surface, which should result in a sizable interaction with it.

Next, we have studied the reaction pathways involving ad-

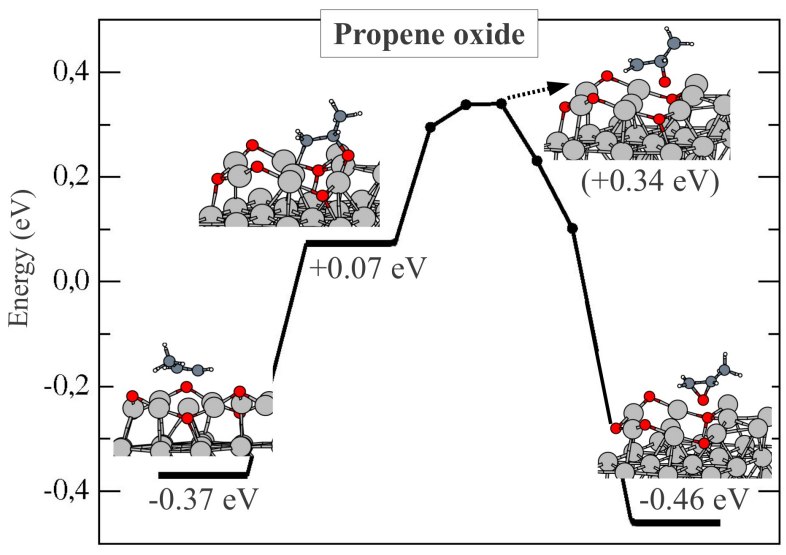

Fig. 5 Pathway for propene oxide formation at the $\mathrm{Ag}_{1.83} \mathrm{O}$ surface oxide. The path involves adsorption of propene and formation of $\mathrm{OMC}$ at non-oxidyzed $\mathrm{Ag}$ atoms. Same energy conventions as in Figure 3.

sorption of propene and OMC formation at non-oxidized $\mathrm{Ag}$ atoms. Figure 5 illustrates the pathway for propene oxide production when propene initially binds at the unoxidized surface Ag atoms. Initial propene adsorption at those sites is slightly stronger than at oxidized $\mathrm{Ag}$ atoms. For the formation of propene oxide, the reaction proceeds in two steps, the first one being the formation of the OMC intermediate, and the second the formation of propene oxide. The first step appears to be the most difficult one, since the OMC intermediate is $0.44 \mathrm{eV}$ less stable than adsorbed propene. Due to this feature, the energy barrier necessary to form propene oxide is very low $(0.27 \mathrm{eV}$, around one half of the corresponding barrier for OMC formed at oxidized $\mathrm{Ag}$ atoms).

The situation for acrolein formation at non-oxidized $\mathrm{Ag}$ atoms is very interesting. The OMC conformation is not favorable towards acrolein production, since the propene methyl group is placed far away from any surface oxygen anion. Therefore, we have analyzed the possibility of hydrogen transfer from the methyl group of intact propene adsorbed at an unoxidized $\mathrm{Ag}$ atom (that is, the configuration shown on Figure 2a). Such process is not feasible, since the energy rises steadily (by about $0.6 \mathrm{eV}$ ) as the hydrogen atom is detached from the $-\mathrm{CH}_{3}$ group while forming a surface hydroxyl (-OH) group. A Transition State is never found, and all along this pathway the forces are driving the hydrogen atom back to propene. This means that we can disregard such process, and therefore conclude that the only possible precursor towards acrolein formation is the OMC conformation.

The underlying motivation for the problematic hydrogen transfer from $\mathrm{Ag}$-adsorbed propene is the weak character of the C-Ag covalent bond which needs to be formed once hy-

This journal is @ The Royal Society of Chemistry [year]

Journal Name, 2010, [vol], 1-8 | 5 
drogen detaches from the methyl group and the $\mathrm{C}=\mathrm{C}$ double bond changes its location within propene. In the acrolein pathway shown in Figure 3, which starts from a OMC conformation, hydrogen abstraction becomes easy (although it requires a small activation energy) because a strong $\mathrm{C}-\mathrm{O}$ covalent bond is already formed. Then, the propene $\mathrm{C}=\mathrm{C}$ double bond is transformed into a $\mathrm{C}-\mathrm{C}$ single bond, and it becomes much easier to transfer the hydrogen atom and to form a $\mathrm{C}=\mathrm{C}$ bond between the methyl group and the central carbon atom. The final conclusion is that, while unoxidized $\mathrm{Ag}$ atoms are reactive towards propene oxide production, the formation of acrolein seems to require a higher degree of oxidation of the $\mathrm{Ag}$ surface.

\section{Reactivity and selectivity at $\mathrm{Ag}_{2} \mathrm{O}$ surface ox- ide}

Finally, we have studied the reactivity and selectivity of the alternate model for the partially oxidized $\mathrm{Ag}$ surface, with $\mathrm{Ag}_{2} \mathrm{O}$ stoichiometry. Figure 6 shows the energy diagram for either propene oxide (upper panel), propanone (middle panel), or acrolein production (lower panel). Overall, the results are qualitatively similar to the ones in Figure 3 (that is, reaction at oxidized Ag atoms). As it was discussed in section III, adsorption of propene is weak, and the relative stability of OMC intermediates is small as well. As for the reaction barrier, we find again barriers of $0.5-0.7 \mathrm{eV}$, indicating the feasibility of the studied reaction pathways at the typical reaction temperatures $\left(100-200{ }^{\circ} \mathrm{C}\right)$. At this point, it is interesting to compare the structural features of the propene oxide transition state in this case with the analogous situations for the $\mathrm{Ag}_{1.83} \mathrm{O}$ model surface. In all cases, the structures of the transition state are remarkably similar, with a C-O bond distance of approximately $2.0 \AA$, and a rather weak interaction with the surface (the bond distance between the oxygen atom within the metallacycle and $\mathrm{Ag}$ surface atoms is quite stretched, of about $2.5 \AA$ ). The direct consequence of the weak TS-surface interaction is a relatively constant value of the binding energy of the transition state on a variety of situations (namely, the type of oxide surface). Such binding energy will be determined alone by the energetic cost (with respect to gas-phase propene oxide, that is, the final state) of breaking one of the $\mathrm{C}$-O bonds (with an equilibrium length of $1.46 \AA$ ) and expanding it to a bond length of around $2.0 \AA$. Therefore, the size of the reaction energy barrier will only depend on the binding energy of the initial state (the OMC intermediate), which actually varies due to both the structural features of the oxide surface and the exact metallacycle conformation.

The formation of propanone takes place starting from the most stable OMC intermediate (the same configuration which is also able to transform into propene oxide). The barrier for

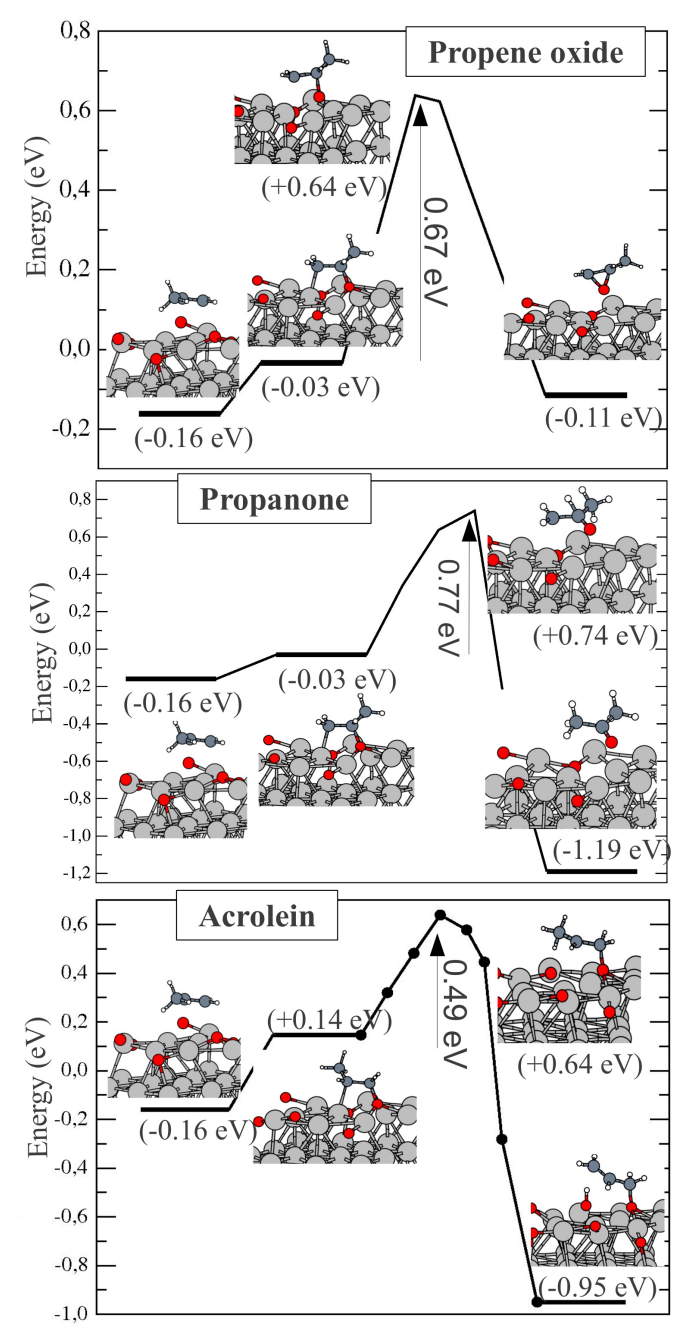

Fig. 6 Pathways for propene oxide (upper panel), propanone (middle panel) and acrolein (bottom panel) formation at the $\mathrm{Ag}_{2} \mathrm{O}$ surface oxide. Same energy conventions as in Figure 3.

hydrogen transfer from the central to the terminal carbon is $0.77 \mathrm{eV}$, about $0.1 \mathrm{eV}$ larger than the barrier for propene oxide formation. Therefore, in this case the surface will be slightly more selective towards propene oxide formation. Again, the possible formation of propanal starting from the OMC configuration in Fig. $2 \mathrm{j}$ cannot be ruled out, although it is quite probable that the energy barrier will be higher that the one found for acrolein formation (the corresponding competitive process).

The barrier for acrolein formation is around $0.2 \mathrm{eV}$ lower than the one for propene oxide formation. However, some care must be taken on comparing both barriers and drawing conclusions about the selectivity, since the initial states for both processes are not the same. Again, in order to obtain a reasonable 
starting configuration, with the propene $\mathrm{CH}_{3}$ group close to a surface oxygen anion, an OMC configuration higher in energy than the global minimum (precisely by around $0.2 \mathrm{eV}$ ) must be considered. This leads to a decrease of the reaction barrier, although the relative stability of the transition states for both propene oxide and acrolein formation are actually the same. The final conclusion is that both types of products are likely to form, probably with similar selectivity towards them.

\section{Conclusions}

In this paper, we have studied the adsorption of propene at two types of oxidized silver surfaces, as well as the possible routes for either its epoxidation or acrolein formation, by reaction with surface oxygen anions. We have also studied formation of propanone. Several important conclusions can be drawn from the results of the ab initio simulations. First of all, propene seems to adsorb preferentially at unoxidized $\mathrm{Ag}$ atoms (assuming that they exist on the surface), meaning that a situation where the catalyst is only partially oxidized will enhance its reactivity. In all cases, the reaction energy barrier for the rate-limiting step (desorption of OMC metallacycle into propene oxide by closing of the C-O-C cycle) lies in the range $0.5-1.0 \mathrm{eV}$, suggesting that the epoxidation reaction can take place at moderate temperatures. Formation of acrolein can also take place with moderate energy barriers, very similar to the ones calculated for propene oxide production. As for the reaction mechanisms, we have found that acrolein formation must necessarily take place from an OMC intermediate. This means that at least two oxygen adatoms must be close to each other on the surface during formation of acrolein, one of them being part of the OMC intermediate, and another one being able to react with the propene methyl group by transfer of one hydrogen atom. This again gives support to the idea of a higher selectivity of partially-oxidized silver surfaces towards propene oxide production.

Considering the case of a partially oxidized silver nanoparticle, where oxygen is expected to concentrate at the most reactive sites (normally low-coordination ones, as edges and corners), the results obtained for extended surfaces suggest that the selectivity will show sizable changes from one type of site to the other. Furthermore, as the relative concentration of highly reactive sites around a nanoparticle depends on its size, a noticeable change in selectivity can be expected for silver nanoparticles of varying size.

Finally, let us mention that propanone can also be formed on this type of system, since the calculated energy barriers are very similar to the ones for propene oxide formation. Neither can we rule out a significant production of propanal; however, a smaller intrinsic stability of the OMC initial state makes propanone formation more probable.
Work supported by the Spanish MICINN and the European Development Fund (grants MAT2008-06483-C03-01 and MAT 2011-22781) and by Junta de Castilla y Leon (grant VA158A11-2). We acknowledge the suport of the spanish supercomputing network (RES) by the computing time allocated at the BSC (Barcelona) and Altamira (University of Cantabria) nodes.

\section{References}

1 T. A. Nijhuis, M. Makkee, J. A. Moulijn and B.M.Weckhuysen, Ind. Eng. Chem. Res., 2006, 45, 3447.

2 T. Hayashi, K. Tanaka and M. Haruta, J. Catal., 1998, 178, 566.

3 M. Haruta, CATTECH, 2002, 6102.

4 J. Huang and M. Haruta, Res. Chem. Intermed. 2012, 38, 1.

5 C. X. Qi, J. H. Huang, S. Q. Bao, H. J. Su, T. Akita and M. Haruta, J. Catal., 2011, 281, 12.

6 S. Lee, L. M. Molina, M. J. Lopez, J. A. Alonso, B. Hammer, B. Lee, S. Seifert, R. E. Winans, J. W. Elam, M. J. Pellin and S. Vajda, Angew. Chem. Int. Ed., 2009, 48, 1467.

7 L. Cumaranatunge and W. N. Delgass, J. Catal., 2005, 232, 38.

8 J. Huang, T. Takei, T. Akita, H. Ohashi and M. Haruta, Appl. Catal. B, 2010, 95, 430.

9 J. Lu, X. Zhang, J.J. Bravo-Suárez, T. Fujitani and S.T. Oyama, Catal. Today, 2009, 147, 186.

10 B. Taylor, J. Lauterbach and W. N. Delgass, Catal. Today, 2007, 123, 50.

11 T. A. R. Nijhuis, T. Visser and B. M. Weckhuysen, Angew. Chem. Int. Ed., 2005, 44, 1115.

12 D. Torres, N. Lopez, F. Illas and R. M. Lambert, Angew. Chem. Int. Ed., 2007, 46, 2055.

13 A. Roldan, D. Torres, J. M. Ricart and F. Illas, J. Mol. Catal A, 2009, 306, 6 .

14 F. R. Negreiros, E. Apra, G. Barcaro, L. Sementa, S. Vajda and A. Fortunelli, Nanoscale, 2012, 4, 1208.

15 A. Kokalj, A. dal Corso, S. de Gironcoli and S. Baroni, Surf. Sci., 2003, 532-535, 191.

16 A. Kokalj, A. dal Corso, S. de Gironcoli, S. Baroni, Surf. Sci., 2004, 566-568, 1018.

17 A. Kokalj, P. Gava, S. de Gironcoli and S. Baroni, J. Phys. Chem. C, 2008, 112, 1019.

18 S. Linic and M. A. Barteau, J. Am. Chem. Soc., 2003, 125, 4034.

19 M. -L. Bocquet, A. Michaelides, D. Loffreda, P. Sautet, A. Alavi and D. A. King, J. Am. Chem. Soc., 2003, 125, 5620.

20 J. R. Monnier and G. W. Hartley, J. Catal., 2001, 203, 253.

21 X. Liu, R. J. Madix and C. M. Friend, Chem. Soc. Rev., 2008, 37, 2243.

22 S. Hawker, C. Mukoid, J. P. S. Badyal and R. M. Lambert, Studies in Surf. Sci. and Catal., 1990, 55, 739.

23 L. M. Molina, S. Lee, K. Sell, G. Barcaro, A. Fortunelli, B. Lee, S. Seifert, R. E. Winans, J. W. Elam, M. J. Pellin, I. Barke, V. von Oeynhausen, Y. Lei, R. J. Meyer, J. A. Alonso, A. F. Rodriguez, A. Kleibert, S. Giorgio, C. R. Henry, K. H. Meiwes-Broer and S. Vajda, Catal. Today, 2011, 160, 116.

24 A. Klust and R. J. Madix, J. Am. Chem. Soc., 2006, 128, 1034.

25 W. Huang, Z. Jiang and J. M. White, Catal. Today, 2008, 131, 360.

26 See DACAPO web page at Danish Technical University: https://wiki.fysik.dtu.dk/dacapo.

27 M.C. Payne, M. P. Teter, D. C. Allan, T. A. Arias and J. D. Joannopoulos, Rev. Mod. Phys., 1992, 64, 1045.

28 D. Vanderbilt, Phys. Rev. B, 1990, 41, 7892. 
29 J. P. Perdew, J. A. Chevary, S. H. Vosko, K. A. Jackson, M. R. Pederson, D. J. Singh and C. Fiolhais, Phys. Rev. B, 1992, 46, 6671.

30 D. C. Liu and J. Nocedal, Math. Program., 1989, 45, 503.

31 A. Alavi, P. Hu, T. Deutsch, P. L. Silvestrelli and J. Hutter, Phys. Rev. Lett., 1998, 80, 3650.

32 W.-X. Li, C. Stampfl and M. Scheffler, Phys. Rev. Lett., 2003, 90, 256102.

33 C. I. Carlisle, D. A. King, M. -L. Bocquet, J. Cerda and P. Sautet, Phys. Rev. Lett., 2000, 84, 3899.

34 A. Michaelides, M. -L. Bocquet, P. Sautet, A. Alavi and D. A. King, Chem. Phys. Lett., 2003, 367, 344.

35 M. -L. Bocquet, A. Michaelides, P. Sautet and D. A. King, Phys. Rev. B, 2003, 68, 075413.

36 M. Schmid, A. Reicho, A. Stierle, I. Costina, J. Klikovits, P. Kostelnik, O. Dubay, G. Kresse, J. Gustafson, E. Lundgren, J. N. Andersen, H. Dosch and P. Varga, Phys. Rev. Lett., 2006, 96, 146102.

37 J. Schnadt, A. Michaelides, J. Knudsen, R. T. Vang, K. Reuter, E. Laegsgaard, M. Scheffler and F. Besenbacher, Phys. Rev. Lett., 2006, 96, 146101.

38 M. -L. Bocquet and P. Loffreda, J. Am. Chem. Soc., 2005, 127, 17207. 